\title{
Multi-Level Interactions between the Nuclear Receptor TRa1 and the WNT Effectors $\beta$-Catenin/Tcf4 in the Intestinal Epithelium
}

\author{
Maria Sirakov $^{1 \times a}$, Seham Skah ${ }^{1 \times b}$, Imtiaz Nisar Lone $^{2}$, Julien Nadjar ${ }^{1 \times b}$, Dimitar Angelov ${ }^{2}$, \\ Michelina Plateroti ${ }^{1 * a b}$
}

1 Institut de Génomique Fonctionnelle de Lyon, Lyon, France, $\mathbf{2}$ Laboratoire de Biologie Moléculaire de la Cellule, Université de Lyon, Université Lyon 1, Ecole Normale Supérieure de Lyon, Lyon, France

\begin{abstract}
Intestinal homeostasis results from complex cross-regulation of signaling pathways; their alteration induces intestinal tumorigenesis. Previously, we found that the thyroid hormone nuclear receptor TR $\alpha 1$ activates and synergizes with the WNT pathway, inducing crypt cell proliferation and promoting tumorigenesis. Here, we investigated the mechanisms and implications of the cross-regulation between these two pathways in gut tumorigenesis in vivo and in vitro. We analyzed TR $\alpha 1$ and WNT target gene expression in healthy mucosae and tumors from mice overexpressing TR $\alpha 1$ in the intestinal epithelium in a WNT-activated genetic background (vil-TR $\alpha 1 /$ Apc mice). Interestingly, increased levels of $\beta$-catenin/Tcf4 complex in tumors from vil-TR $\alpha 1 /$ Apc mice blocked TR $\alpha 1$ transcriptional activity. This observation was confirmed in Caco2 cells, in which TR $\alpha 1$ functionality on a luciferase reporter-assay was reduced by the overexpression of $\beta$-catenin/Tcf4. Moreover, TR $\alpha 1$ physically interacted with $\beta$-catenin/Tcf4 in the nuclei of these cells. Using molecular approaches, we demonstrated that the binding of TR $\alpha 1$ to its DNA target sequences within the tumors was impaired, while it was newly recruited to WNT target genes. In conclusion, our observations strongly suggest that increased $\beta$-catenin/Tcf4 levels i) correlated with reduced TR $\alpha 1$ transcriptional activity on its target genes and, ii) were likely responsible for the shift of TR $\alpha 1$ binding on WNT targets. Together, these data suggest a novel mechanism for the tumor-promoting activity of the TR $\alpha 1$ nuclear receptor.
\end{abstract}

Citation: Sirakov M, Skah S, Lone IN, Nadjar J, Angelov D, et al. (2012) Multi-Level Interactions between the Nuclear Receptor TR $\alpha 1$ and the WNT Effectors $\beta$ Catenin/Tcf4 in the Intestinal Epithelium. PLoS ONE 7(4): e34162. doi:10.1371/journal.pone.0034162

Editor: Masaru Katoh, National Cancer Center, Japan

Received November 16, 2011; Accepted February 23, 2012; Published April 3, 2012

Copyright: (c) 2012 Sirakov et al. This is an open-access article distributed under the terms of the Creative Commons Attribution License, which permits unrestricted use, distribution, and reproduction in any medium, provided the original author and source are credited.

Funding: This work was supported by the Institut National pour le Cancer (grant INCA-2009-175) and the Ligue contre le Cancer Department du Rhone. The funders had no role in study design, data collection and analysis, decision to publish, or preparation of the manuscript.

Competing Interests: The authors have declared that no competing interests exist.

* E-mail: michela.plateroti@ens-lyon.fr

aa Current address: Institut de Biologie et de Médecine Moléculaires, Université libre de Bruxelles, Bruxelles, Belgium ab Current address: Centre de Génétique et de Physiologie Moléculaire et Cellulaire, Université Lyon 1, Lyon, France

\section{Introduction}

The intestinal epithelium is a dynamic tissue that is continuously renewed through stem cells and committed progenitors, located in the crypts of Liberkün $[1,2]$. The balance between proliferation and differentiation in the crypts is maintained by the fine crossregulation among several pathways, including WNT, Hedgehog, Notch, BMP, and thyroid hormones (THs) [3-6]. These pathways are key players of intestinal homeostasis, and their deregulation is correlated with the onset of colorectal cancer [7-9]. The molecular basis of their action is only partially understood, and the mechanism of cross-regulation that occurs between these signaling pathways is still a puzzle. We previously demonstrated that $\mathrm{TH}$ signaling in the mouse intestine is involved in development, homeostasis and cancer susceptibility [10]\#. THs act through nuclear hormone receptors, the TRs, which are encoded by THRa and THRb loci [11]. These transcription factors activate or repress the transcription of target genes by binding to specific DNA sequences called thyroid hormone response elements (TREs) [12], and they are involved in several cellular responses, such as cell proliferation, cell differentiation and apoptosis [5,13]. TH signaling in the mouse intestine is mediated by TR $\alpha 1$, given that $\mathrm{TR} \alpha^{0 / 0}[14]$ mice as well as hypothyroid mice have reduced cell proliferation in the crypts during development and in adulthood [15]. Recently, we showed that the constitutive TR $\alpha$ l overexpression in the intestinal epithelium (vil-TR $\alpha 1$ mice) allows increased cell proliferation and adenoma development; this overexpression also enhances the intestinal tumorigenic process in an Apc mutated genetic background (vil-TR $\alpha 1 / \mathrm{Apc}^{+/ 1638 \mathrm{~N}}$ mice) [9]. Interestingly, one of the molecular features of the vilTR $\alpha 1 / A p c$ mice is the increased activity of the WNT pathway compared with that of the Apc mutants [9]. This is in agreement with our previous studies showing that TR $\alpha 1$ activates the WNT pathway via the transcriptional regulation of the genes Ctnnb1 and Sfrp2 $[15,16]$.

$\beta$-Catenin, the protein encoded by Ctnnb1, was originally identified as a structural component of cell adhesion complexes [17]. Upon increased cellular levels and nuclear accumulation, $\beta$ catenin interacts with transcription factors of the T-cell factor (Tcf) and lymphocyte-enhancer factor (Lef) families [18]. $\beta$-catenin/ 
Tcf-Lef complexes are the downstream molecular effectors of the WNT signaling pathway. They bind to WNT response elements (WREs) in the genomic region of target genes involved in cell proliferation, survival, and migration $[7,19]$. In the context of the intestinal epithelium, the $\beta$-catenin/Tcf4 complex regulates the expression of genes involved in the development and proliferation of normal and malignant epithelia [20,21]. $\beta$-catenin, however, forms complexes with other transcription factors, including nuclear hormone receptors [22,23]. This interaction modulates the transcriptional activity of the partners, depending on the specific tissue or nuclear receptor [24-28]. Our previous studies on the relationship between WNT and TR $\alpha 1$, combined with these observations, compelled us to investigate the physical interaction between TR $\alpha 1$ and $\beta$-catenin, the eventual involvement of Tcf4 in the complex, and its physiopathological relevance.

We established that the increased levels of the $\beta$-catenin/Tcf4 complex affects the transcriptional activity of TR $\alpha 1$ in vivo. We show that TR $\alpha 1$ interacts with the $\beta$-catenin/Tcf4 complex in the nuclei of Caco2 cells and that this interaction strongly reduces TR $\alpha 1$ functionality, but has a positive effect on the WNT downstream response in vitro. Finally, we observed the recruitment of $T R \alpha 1$ on the WRE regions in pre-cancerous and cancerous intestinal lesions.

\section{Results}

\section{The expression of $\mathrm{TR} \alpha 1$ direct target genes is impaired in} vil-TR $\alpha 1 /$ Apc mice

We analyzed the expression profile of TR $\alpha 1$ target genes in normal mucosae or tumors from mice of different genotypes to gain additional insights on the cross-regulation between TR $\alpha 1$ and WNT pathways in gut tumorigenesis. Six-month-old vil-TR $\alpha 1$ [9], $\mathrm{Apc}^{+/ 1638 \mathrm{~N}}$ [29] and double-mutant vil-TR $\alpha 1 / \mathrm{Apc}$ [9] mice were analyzed. The vil-TR $\alpha 1$ mice are characterized by hyperproliferation in the intestinal crypts and a low rate of adenoma development in the small intestine and colon [9]. The $\mathrm{Apc}^{+/ 1638 \mathrm{~N}}$ develop a small number of adenocarcinomas, starting at approximately six months of age; these tumors occur primarily in the small intestine [29,30]\#. The vil-TR $\alpha 1 /$ Apc mice develop adenocarcinomas in the small intestine and colon at a higher frequency than do the Apc mutants. Moreover, the tumor appearance and progression to invasiveness are also accelerated in these mice. Finally, WNT activity in the tumors of these animals is increased compared with Apc mutants [9].

We compared the expression profiles of Ctnnb1 and Sfrp2, TR $\alpha 1$-direct target genes [15,16], and of Ccnb1 and Cdc2a, TR $\alpha 1$ indirect target genes [16]. For Ctnnb1 and Sfrp2, we observed an increased mRNA levels in the vil-TR $\alpha 1$ mice compared with the WT mice, while in the normal mucosa or tumors of the Apc mice, the mRNA levels slightly decreased (Ctnnb1, Figure 1A) or did not change (Sfrp2, Figure 1B). However, in the vil-TR $\alpha 1 /$ Apc mice, the up-regulation of both genes was blunted, and the mRNA level unchanged (Ctnnb1, Figure 1A) or decreased (Sfrp2, Figure 1B) in the tumors. When we examined the $\mathrm{TR} \alpha \mathrm{l}$-indirect target genes Ccnb1 and $C d c 2 a$, we observed that $\mathrm{TR} \alpha 1$ overexpression stimulated the mRNA levels of these genes independently of the Apc mutation (Figure 1C, D). We also analyzed the Ctnnb1 and Sfrp 2 mRNA expression in one-month-old animals. In fact, the tumorigenic program triggered by the loss of Apc heterozygosis [30] at that age is not yet accomplished, and the vil-TR $\alpha 1 / \mathrm{Apc}$ mice do not yet show any signs of mucosal alteration. Interestingly, the mRNA expression level of $\mathrm{TR} \alpha 1$-direct target genes in these animals was comparable with that of the vil-TR $\alpha 1$ mice, and in both cases, significantly higher than in the WT intestine
(Figure S1A, B). We excluded the fact that the TR $\alpha 1$-reduced transcriptional activity is due to a lower availability of hormones, as the circulating TH level is not altered in the animals of different genotypes [9]. However, the intracellular concentration of $\mathrm{TH}$ may depend on T3 and T4 metabolism, which is locally regulated by the iodothyronine deiodinase selenoenzymes (Dio1, Dio2 and Dio3) [31,32]. Next, we considered the possibility that the transcriptional activity of $\mathrm{TR} \alpha \mathrm{l}$ was reduced by local hypothyroidism within the tumors and checked the levels of the three enzymes. However, when we analyzed the expression of the Dio mRNAs, we observed that only Diol was expressed, and its levels did not change in the intestine of different genotypes or in the tumors (Figure S1C), confirming that the cellular context was not hypothyroid. It is worth noting that in another context, Diol has been shown to be TH-responsive [31]; however, this difference may be due to the well-described tissue-specific regulation of $\mathrm{TH}$ target genes [10].

\section{The Wnt3a ligand is not sufficient to affect $T R \propto 1$ transcriptional activity in an ex vivo assay}

We used intestinal epithelial primary culture to evaluate whether activation of the WNT pathway by an agonist could impair TR $\alpha 1$ transcriptional activity. To selectively modulate TR $\alpha 1$ and WNT, we treated the cells with T3 and the canonical Wnt3a ligand [33] alone or in combination. We observed that T3 and/or Wnt3a increased the number of proliferating cells (Figure 2A) and expressing nuclear $\beta$-catenin [Figure 2B]. The increase of both activated $\beta$-catenin protein level (Figure $2 \mathrm{G}$ ) and Cond1 mRNA expression (Figure 2D), indicated that the cells were responding to the simple treatments as previously shown $[15,34]$. When we investigated the expression of Ctnnb1 and Sfrp2, TR $\alpha 1$ direct target genes, both mRNA levels increased upon T3 treatment, as expected. Wnt3a had no effect on Ctnnb1 mRNA (Figure 2E) but stimulated Sfpr2 mRNA (Figure 2F). Finally, when the cells were treated with Wnt3a and T3, the TR $\alpha 1$ targets behaved as they did when treated only with T3, because they were not affected by the co-treatment with Wnt3a (Figures 2E, F). The expression of TR $\alpha 1$ or Tcf4 was not altered by $\mathrm{T} 3$ alone or in combination with Wnt3a (not shown).

\section{Tcf7/2 (Tcf4) is overexpressed in vil-TR $\alpha 1 / A p c$ mice}

The data obtained using the in vitro and in vivo approaches strongly suggested that $\beta$-catenin stabilization induced by Wnt3a is not sufficient to impair TR $\alpha 1$ transcriptional activity. Thus, the hypothesis that an increased level of both $\beta$-catenin and Tcf4 could affect $T R \alpha 1$ functionality was tested. We examined the mRNA expression of Tcf4 in the normal intestine and tumors from animals of different genotypes. The Tcf4 mRNA expression in vil-TR $\alpha 1$ or the normal mucosa of Apc mice was similar to that of WT animals (Figure 3A). However, the mRNA level significantly increased in the normal mucosa of the vil-TR $\alpha 1 / \mathrm{Apc}$ mice and was even further upregulated in the tumors. We also observed an increased level of Tcf4 mRNA in the lesions from Apc mice compared with the healthy mucosa (Figure 3A). This trend was different from that observed for Lef1 mRNA, another transcriptional partner of $\beta$-catenin in the intestine $[35,36]$. In fact, Lef1 mRNA level was significantly increased only in the lesions independently of the animals' genotype (Figure 3B).

Finally, we analyzed the expression of Cond 1 and $c-M y c$, the WNT target genes, and we observed their significant upregulation in the vil-TR $\alpha 1$ and in the normal mucosa of vil-TR $\alpha 1 /$ Apc mice compared with that of the WT or the normal mucosa of Apc mice [Figure 3C, D], in accordance with our previous results [9]. The expression level of these WNT target genes significantly increased 
A

B

Ctnnb1
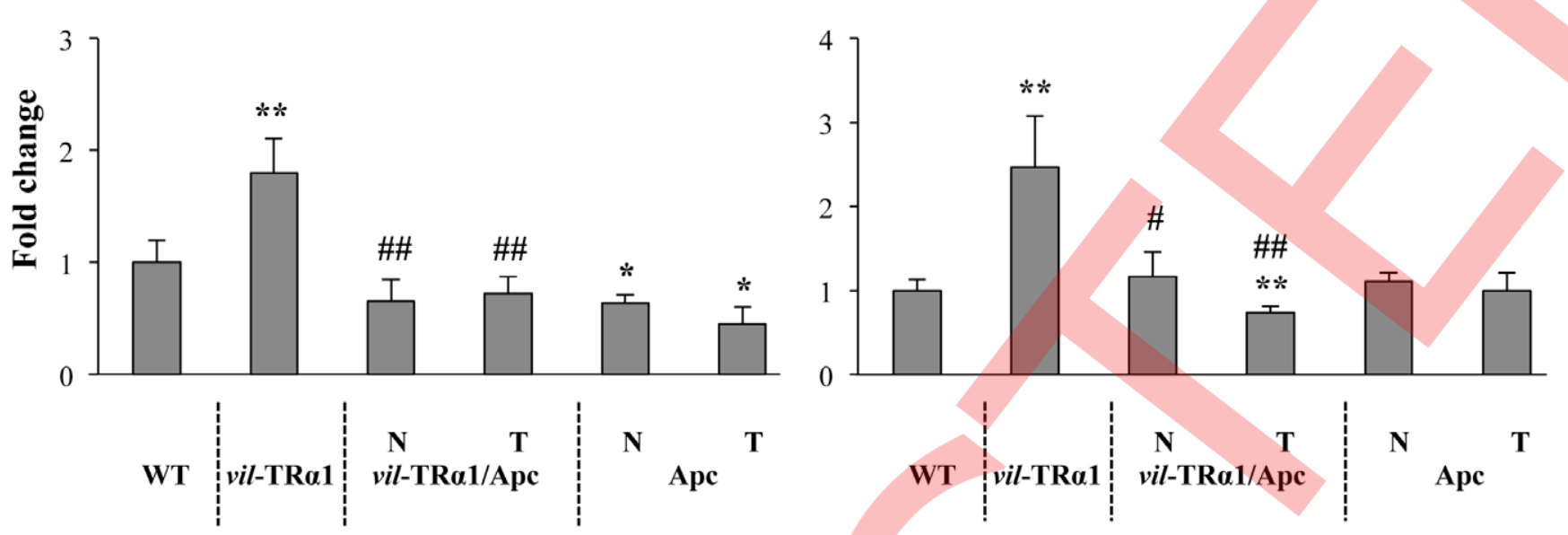

C

\section{D}

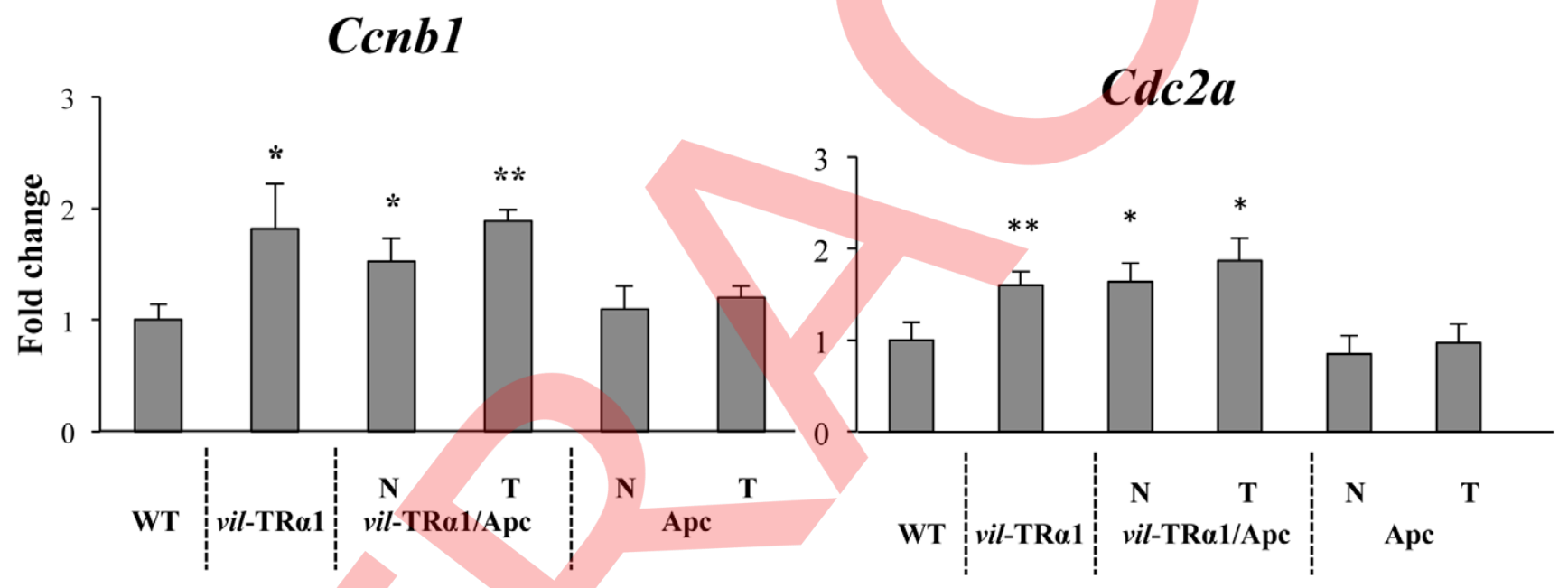

Figure 1. Analysis of TRa1 target genes in mice of different genotypes. RT-qPCR experiments were performed in the intestine of 6-monthold mice of the indicated genotype to analyze the mRNA levels of Ctnnb1 (A), Sfrp2 (B), Ccnb1 (C) and Cdc2a (D). Values represent fold change \pm sd after normalization to the wild-type [WT] animals. *: $\mathrm{P}<0.05$, *: $\mathrm{P}<0.001$, compared with the WT; \#: $\mathrm{P}<0.05$, \#\#: $\mathrm{P}<0.01$ compared with the vil-TR $\alpha 1$ animals, by two-tailed Student's t-test $(n=4)$. N, normal mucosa; $T$, tumor. doi:10.1371/journal.pone.0034162.g001

in the tumors of both genotypes compared with the respective normal mucosae (Figure 3C, D).

\section{The $\beta$-catenin/Tcf 4 complex interferes with TR $\alpha 1$} functionality in vitro

The data described above strongly suggested that a negative feedback loop could occur between TR $\alpha 1$ and the $\beta$-catenin/Tcf4 complex. To test this hypothesis, we used a luciferase reporter system containing a synthetic tandem of TR-binding sites organized as DR4 (DR4-luc) [15] and monitored its response upon $\beta$-catenin and/or Tcf4 transfection. These experiments were performed in Caco2 cells maintained in T3-depleted serum with and without the addition of a supra-physiological concentration of T3 (Figure 4A). In the control condition, we observed a strong and significant increase in luciferase activity upon T3 treatment due to the presence of endogenous $\mathrm{TR} \alpha \mathrm{l}$. It is worth noting that we observed a response to $\mathrm{T} 3$ addition in all conditions analyzed (Figure 4A). The transfection of $\beta$-catenin alone did not affect the DR4-luc response to the endogenous TR $\alpha 1$ stimulated by T3, while Tcf4 alone slightly reduced the reporter activity. Interestingly, Tcf4 in combination with $\beta$-catenin significantly reduced the T3 response of the endogenous TR $\alpha 1$ compared with the control (Figure 4A). As expected, the TR $\alpha 1$ transfection in the cells treated with T3 significantly enhanced the luciferase activity in comparison with the control (Figure 4A). This T3-mediated response in $\mathrm{TR} \alpha 1$-transfected cells was slightly reduced in the presence of $\beta$ catenin, significantly decreased in the presence of Tcf4 and a stronger negative effect was observed by combining Tcf4 and $\beta$ catenin co-transfection.

We also measured the DR4-luc activity in cells maintained in culture medium containing physiological concentrations of T3 [37] (Figure 4B). As expected, TR $\alpha$ l transfection significantly induced the luciferase activity compared with the control. 
A

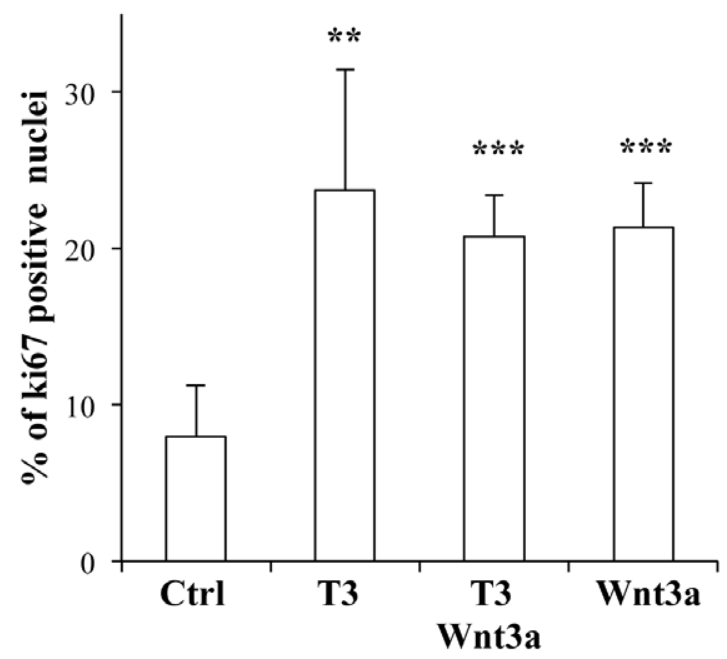

B

Nuclei $\beta$-catenin Merging

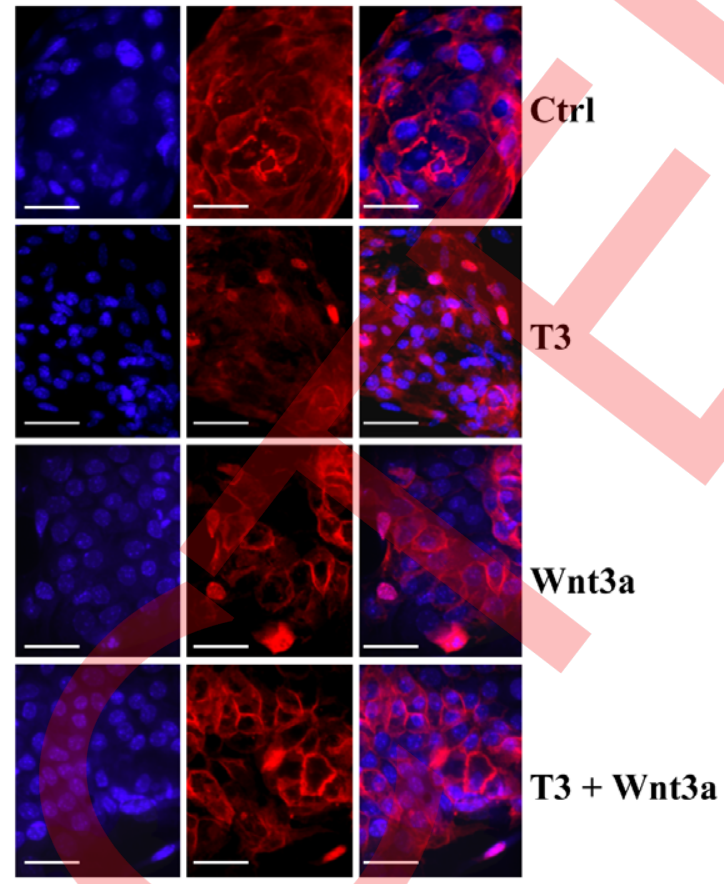

D

\section{Ccnd1}

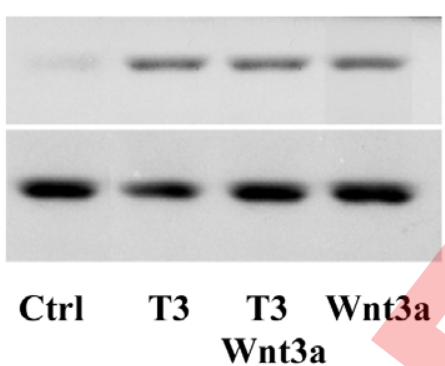

Activated$\beta$-catenin

Actin

E

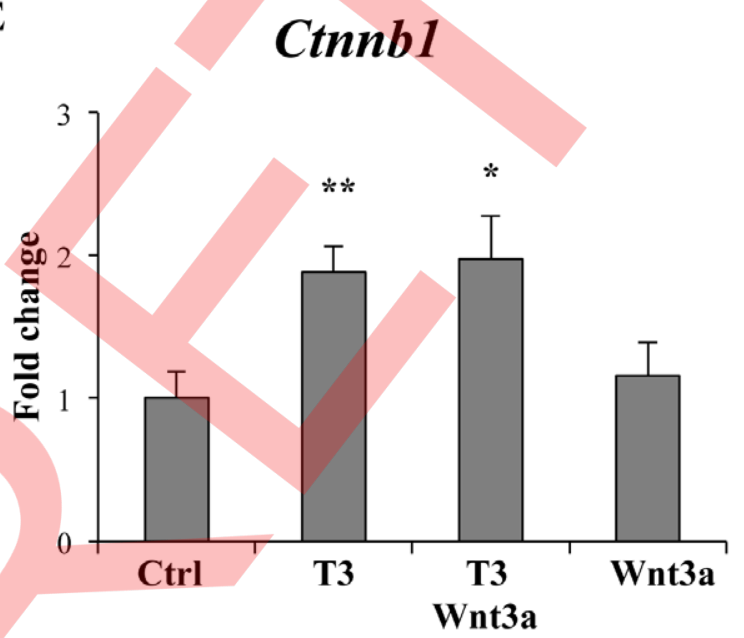

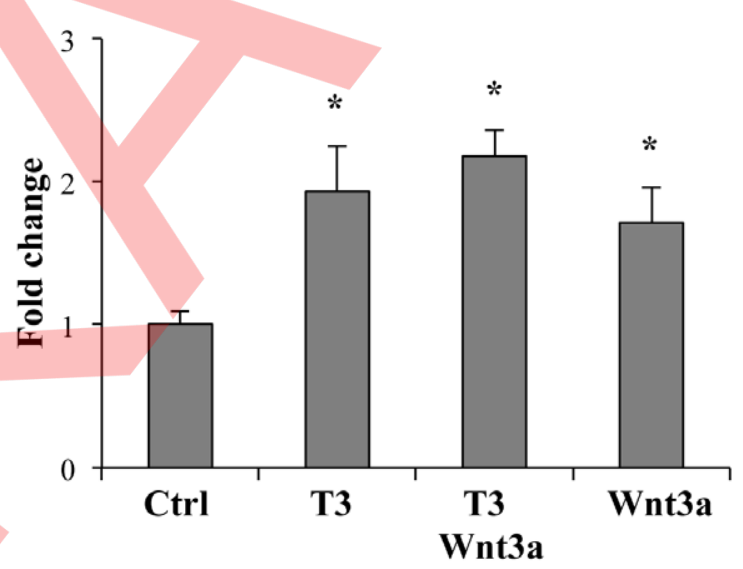

F

Sfrp2

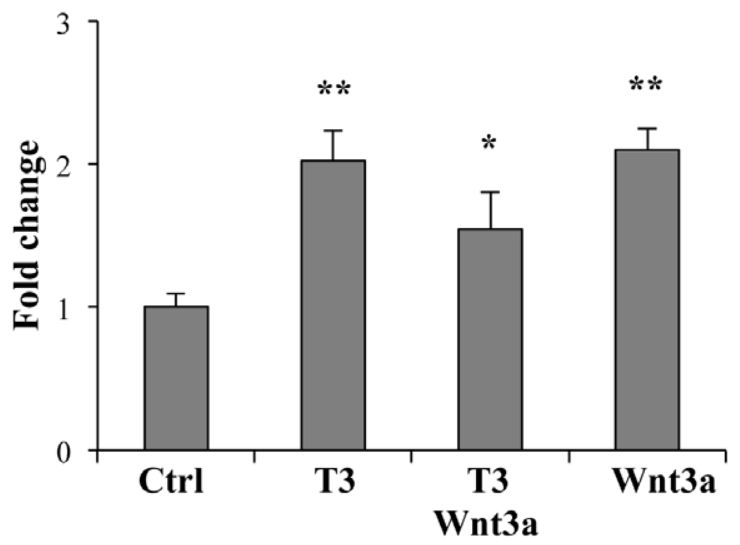


Figure 2. The Wnt3a ligand is not sufficient to impair TR $\alpha 1$ transcriptional activity ex vivo. The primary cultures of intestinal epithelial cells were treated with $10 \mathrm{ng} / \mathrm{ml}$ of Wnt3a and/or $10^{-7} \mathrm{M}$ of T3 for 24 hours. (A) The number of proliferating cells in the different experimental conditions was analyzed by Ki67 immunolabeling; all of the nuclei were labeled by Hoechst. The percentage of Ki67-positive nuclei was determined by counting under a fluorescence microscope (Zeiss Axioplan). The histograms represent the summary (mean \pm sd) of the scoring of specific immunolabeling in two independent experiments each conducted in triplicate $(n=50)$. (B, C) Analysis of $\beta$-catenin in intestinal epithelial primary cultures by immunolabelling (B) and WB (C). Cells were in control, T3, Wnt3a and T3+Wnt3a conditions as indicated. Pictures in B show the fluorescent staining of the nuclei (blue), $\beta$-catenin (red) and the merging of each simple labeling. Bar: $15 \mu \mathrm{m}$. For the WB (C), we used a specific antibody allowing the detection of activated non-phosphorylated $\beta$-catenin $[54,55]$. Actin was used as loading control. The image is representative of two independent experiments. Each lane represents whole protein extracts $(50 \mu \mathrm{g} / \mathrm{lane})$. (D-F) RT-qPCR analysis to evaluate mRNA levels of $C \mathrm{cnd1}$, Ctnnb1 and Sfrp2. Results are from three independent experiments, each conducted in duplicate. Values represent fold change \pm sd after normalization to the control condition (Ctrl). ${ }^{*}: P<0.05,{ }^{* *}: P<0.01,{ }^{* * *}: P<0.001$ by two-tailed Student's t-test $(n=6)$. doi:10.1371/journal.pone.0034162.g002

Moreover, this response was impaired by co-transfection of TR $\alpha 1$ with the $\beta$-catenin and Tcf4 vectors. The luciferase activity induced by $\mathrm{TR} \alpha \mathrm{l}$ overexpression was not affected by $\beta$-catenin alone but was slightly reduced by Tcf4 (Figure 4B). We decided to verify if these combinatory transfections could also affect the activity of the WNT-reporter system TopFlash, which responds to
A

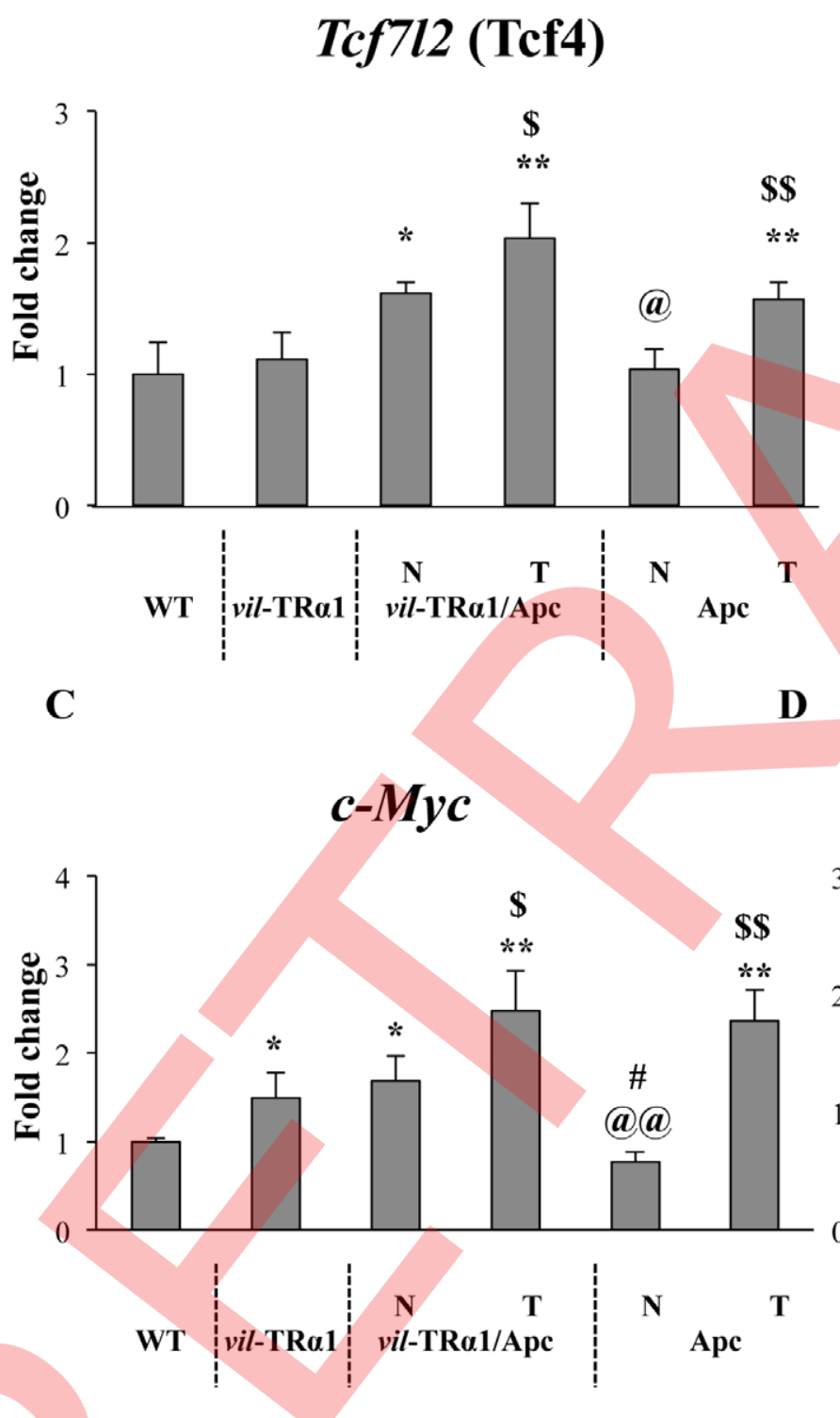

)
B

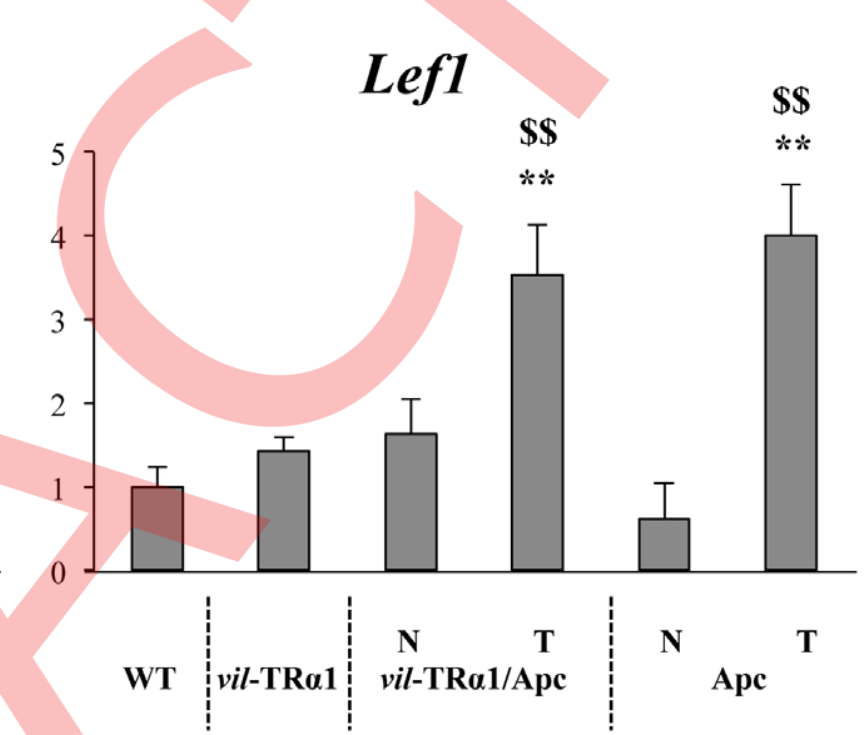

\section{Ccnd1}

Figure 3. Analysis of $T c f 7 / 2$ (Tcf4) and Wnt target genes in mice of different genotypes. RT-qPCR experiments were performed in the intestine of 6-month-old mice of the indicated genotype. (A) Tcf4, (B) Lef1, (C) c-Myc and (D) Ccnd1 mRNA levels were analyzed. Values represent fold change $\pm s d$ after normalization to wild-type (WT) animals. *: $P<0.05$, **: $P<0.01$ compared with the WT; $\$: P<0.05, \$$ : $P<0.01$ compared with the healthy mucosa of the same genotype; @: $\mathrm{P}<0.05$, @@: $\mathrm{P}<0.01$ compared with vil-TR $\alpha 1 / \mathrm{Apc} \mathrm{N}$ and $\mathrm{T} ; \#$ : $\mathrm{P}<0.05$ compared with vil-TR $\alpha 1$, by twotailed Student's t-test $(n=4)$. N, normal mucosa; T, tumor.

doi:10.1371/journal.pone.0034162.g003 
A

\section{Relative Luciferase Units}
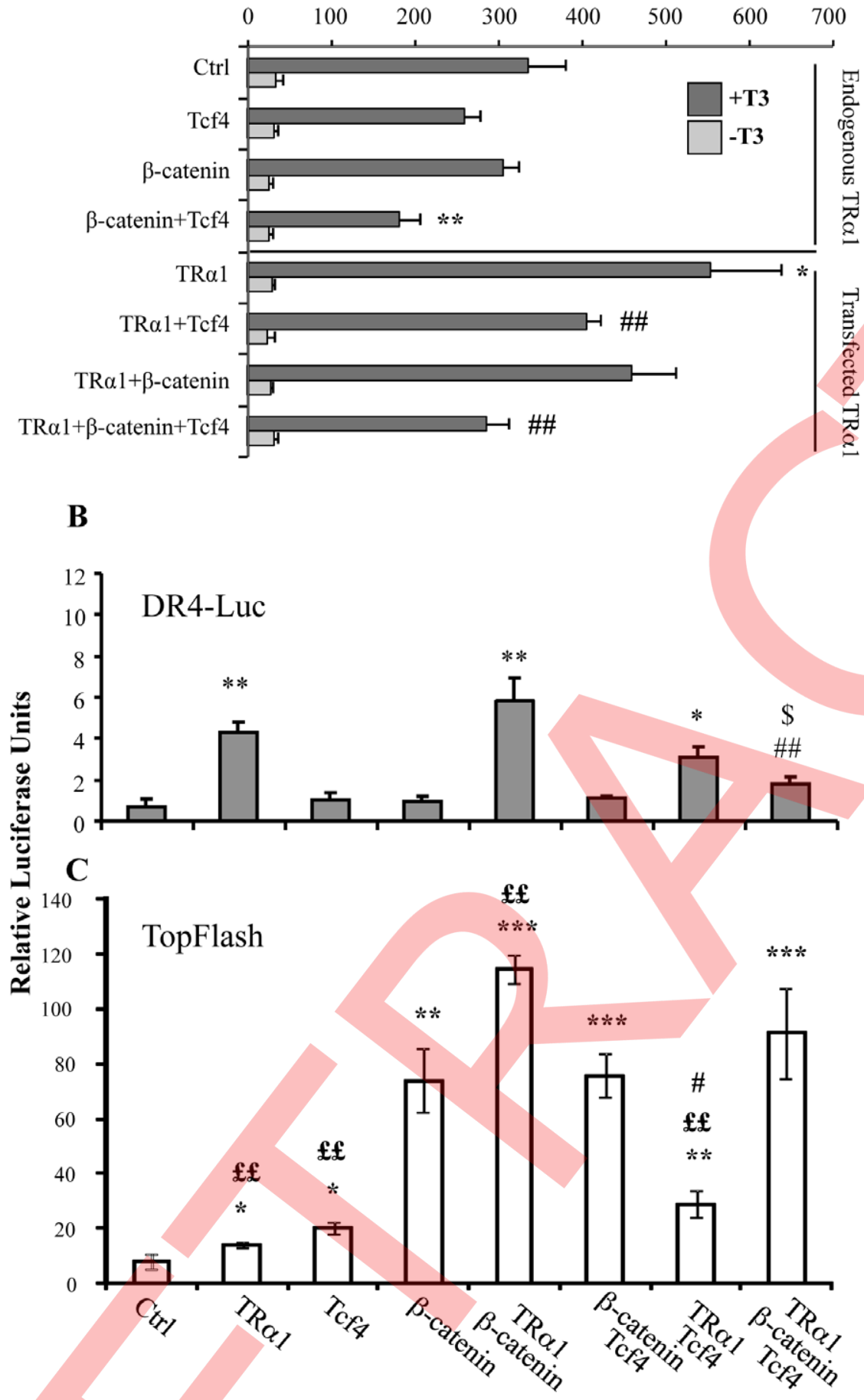

Figure 4. $\beta$-catenin/Tcf4 complex interferes with TRa1 functionality in luciferase assay in vitro. (A) The DR4-luc luciferase reporter was transfected into $\mathrm{Caco} 2$ cells maintained in T3-depleted serum with or without supplementation with T3 as indicated, together with TR $\alpha 1$, Tcf4 or $\beta$ catenin expression vectors in different combinations. (B, C) The DR4-luc luciferase reporter (B) or TopFlash luciferase reporter (C) was transfected into $\mathrm{Caco} 2$ cells maintained in culture medium containing physiological concentrations of T3, together with the $\beta$-catenin/Tcf 4 complex in the presence or absence of the TR $\alpha 1$ expression vector. Histograms represent mean $\pm s d$ from three independent experiments, each conducted in triplicate $(n=9)$. *: $\mathrm{P}<0.05$, **: $\mathrm{P}<0.01$ compared with the control condition (Ctrl); \#: $\mathrm{P}<0.05$, \#\#: $\mathrm{P}<0.01$, compared with the TR $\alpha 1$ condition; $\$: \mathrm{P}<0.05$ compared with the TR $\alpha 1+\beta$-catenin condition; $£ £$ : $\mathrm{P}<0.01$ compared with the $\beta$-catenin or $\beta$-catenin+Tcf4 condition, by two-tailed Student's t-test. doi:10.1371/journal.pone.0034162.g004 
the $\beta$-catenin/Tcf complex [38]. We observed a significant increase of TopFlash activity when TR $\alpha 1$ was transfected together with $\beta$-catenin or Tcf4 compared with the simple $\beta$-catenin or Tcf4 conditions (Figure 4C). We observed a slight up-regulation of the TopFlash activity, marginally significant, when TR $\alpha 1$ was transfected together with $\beta$-catenin/Tcf4. We verified the specificity of these responses by using mutated DR4-luc or FopFlash reporters (data not shown).

\section{TR $\alpha 1$ binding on chromatin changes during gut tumorigenesis}

Our findings strongly indicated that the increased level of the $\beta$ catenin/Tcf4 complex significantly reduced the TR $\alpha 1$ transcriptional activity both in cell lines and in vivo. To define the mechanism involved, we evaluated whether TR $\alpha 1$ could physically interact with $\beta$-catenin and/or Tcf4, as has been shown for other nuclear receptors $[22,23]$. For this purpose, a co-immunoprecipitation (Co-IP) approach was employed to selectively target the endogenous proteins in the nuclei of Caco2 cells. After validating that $\mathrm{TR} \alpha 1$ and $\beta$-catenin interact specifically in cell nuclei (Figure S2), we also analyzed the involvement of Tcf4. Interestingly, we observed that in the nuclei of the Caco2 cells the endogenous TR $\alpha 1$ is associated with $\beta$-catenin (Figure 5, upper and middle panels) as well as with Tcf4 (Figure 5, upper and lower panels). Moreover, all these interactions do not depend on T3 levels.

We then investigated the presence of the three proteins on the chromatin, by using an in vivo chromatin immunoprecipitation (ChIP) approach to analyze the TREs and WREs of the specific target genes of TR $\alpha 1$ and WNT, respectively. The ChIP assay was performed on WT intestine and the normal mucosa or tumors from vil-TR $\alpha 1 / A p c$ mice using anti-TR $\alpha 1$, anti-Tcf4, anti- $\beta$ catenin antibodies or rabbit IgG (as negative control). As shown in Figures $6 \mathrm{~A}$ and $\mathrm{S} 3 \mathrm{~A}$, in the WT intestine, $\mathrm{TR} \alpha \mathrm{l}$ binds to the promoter region of the Sfrp2 gene, which contains the TRE [16]; however, there was no recruitment of the $\beta$-catenin/Tcf4 complex

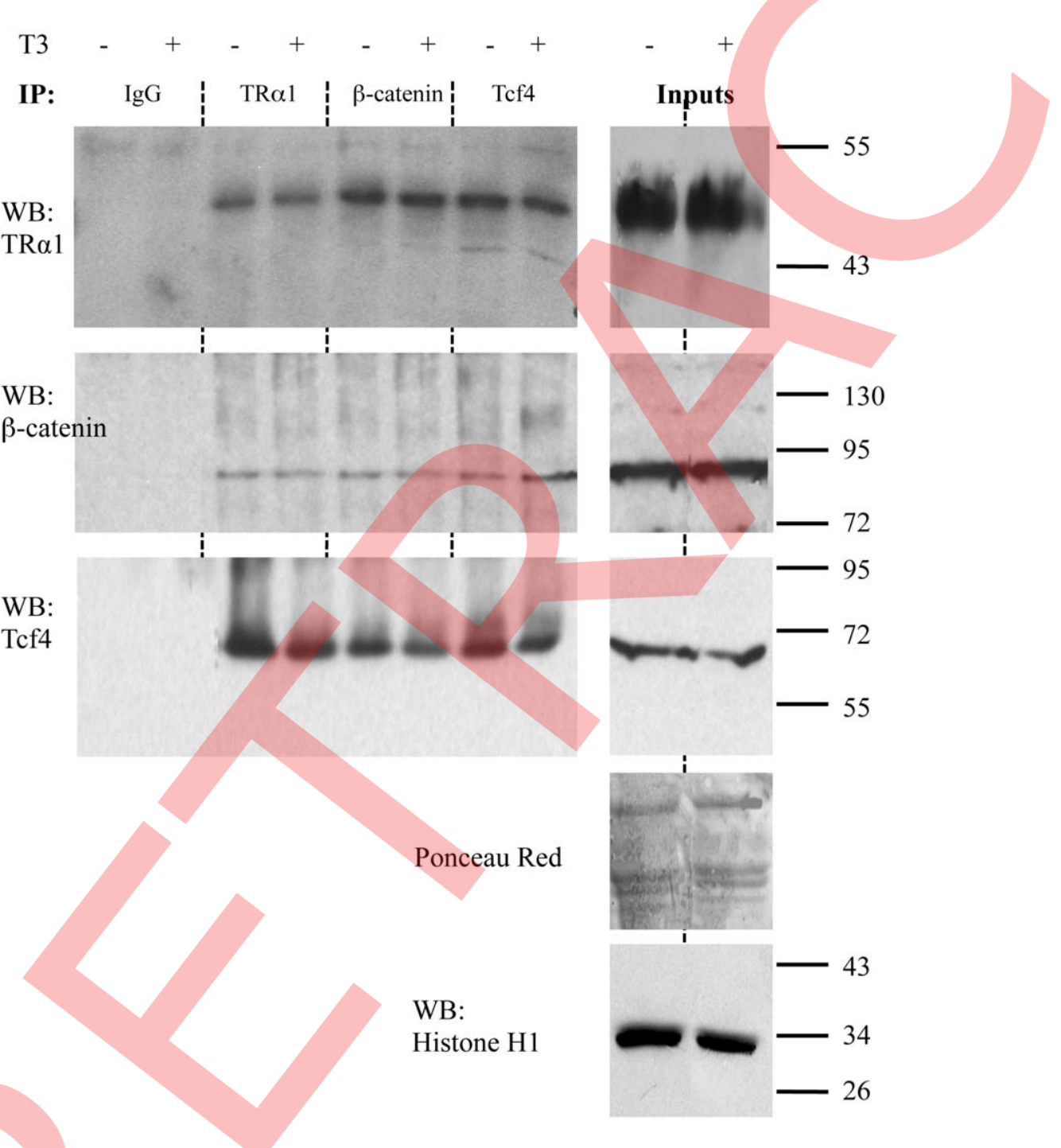

Figure 5. Physical interaction between TR 1 and the $\beta$-catenin/Tcf4 complex. Nuclear extracts from Caco2 cells, maintained in T3-depleted $(-)$ or T3-supplemented (+) serum, were immunoprecipitated with antibodies directed against endogenous Tcf4, $\beta$-catenin or TR $\alpha 1$ and analyzed by WB by using the antibodies as indicated. Rabbit lgG was used as negative control. Ponceau red was used as whole-protein (50 $\mu \mathrm{g} / \mathrm{lane})$ loading control. Histone $\mathrm{H} 1$ was used to check the enrichment and was the loading control for the nuclear proteins in the inputs. The pictures are representative of at least three independent experiments.

doi:10.1371/journal.pone.0034162.g005 
A
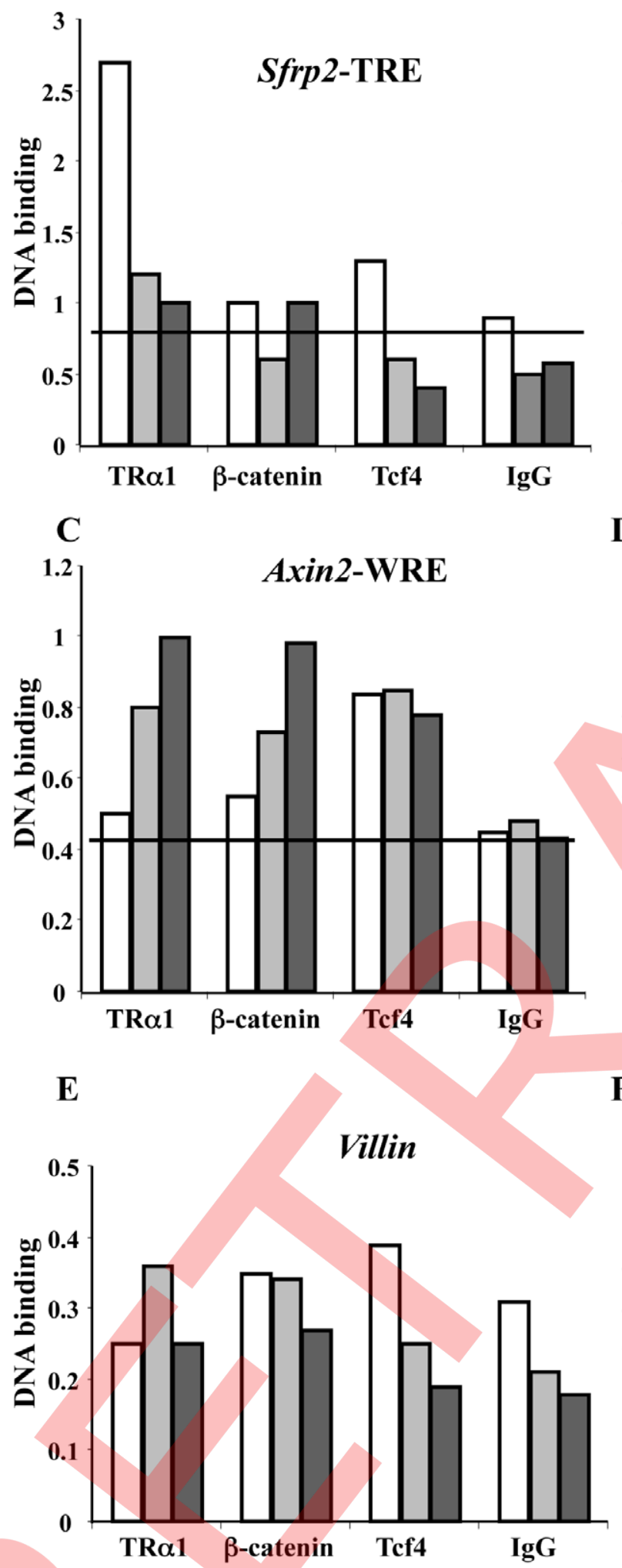

D
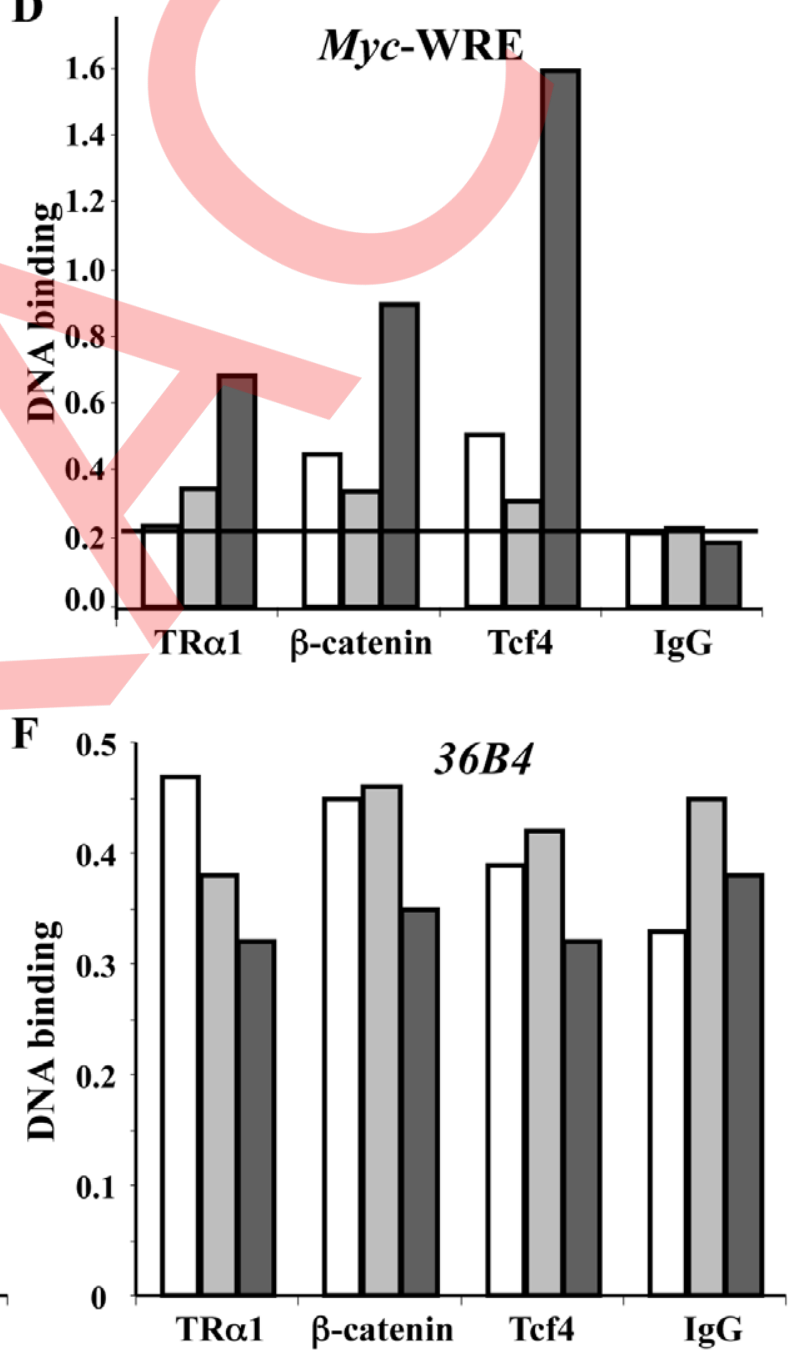

\section{$\square \mathrm{WT}$}

\section{$\square$ vil-TR $\alpha 1 /$ Apc N}

$\square$ vil-TR $\alpha 1 /$ Apc T 
Figure 6. Chromatin occupancy of TRa1, $\beta$-catenin and Tcf4 on genomic regions of target genes. ChIP analysis was performed with chromatin isolated from the intestine of WT or vil-TR $\alpha 1 / A p c$ mice (healthy mucosa and tumor) and immunoprecipitated with anti-TR $\alpha 1$, anti- $\beta$ catenin, anti-Tcf4 antibodies or rabbit lgG (negative control). qPCR was performed using specific primers covering the TRE of Sfrp2 (A) and Ctnnb1 (B), the WRE of Axin2 (C) and c-Myc (D) or the promoters of Villin (E) and $36 B 4(\mathrm{~F})$; the Ppia gene was used as internal control. Data are representative of one of two experiments. Histograms represent the specific-DNA enrichment in each sample immunoprecipitated with the indicated antibody. The black bar in A-D delineates the threshold of binding specificity determined by the IgG non-specific binding. N, normal mucosa; T, tumor. doi:10.1371/journal.pone.0034162.g006

independently of the genotype or the pathological condition (Figures 6A and S3A). This result was similar to that obtained by an in vitro EMS assay in which TR $\alpha 1$ binds to a DR4 element without forming a complex with $\beta$-catenin and/or Tcf4 (Figure S4). As the Sfrp2 expression profile suggested, the TR $\alpha 1$ chromatin occupancy changed between the WT and mutant intestine. In fact, in vil-TR $\alpha 1 / \mathrm{Apc}$ mice, the TR $\alpha 1$-specific-DNA binding on the promoter was lost compared with the WT animals (Figures $6 \mathrm{~A}$ and $\mathrm{S} 3 \mathrm{~A})$. We confirmed this same profile of $\mathrm{TR} \alpha 1$ chromatin occupancy on the Ctnnb1 TRE [15] (Figures 6B and S3B).

Next, we analyzed the specific DNA binding of Tcf4 and $\beta$ catenin on their target genes and the eventual presence of $T R \alpha 1$ in the same regions. A WRE has been described within the Axin2 promoter [39]. We observed that the Tcf4 occupancy on this promoter was similar in the different experimental conditions (Figures $6 \mathrm{C}$ and $\mathrm{S} 3 \mathrm{C}$ ) and that the presence of $\beta$-catenin on the WRE increased during tumorigenesis. More interestingly, TR $\alpha 1$ was not present on the Axin2 WRE region in the WT intestine but was clearly enriched on it, both in normal mucosae and the tumors of vil-TR $\alpha 1 /$ Apc mice (Figures $6 \mathrm{C}$ and S3C). We confirmed a similar trend of TR $\alpha 1$ binding on the WRE region of $c-M y c$, another classical direct WNT target [40] (Figures 6D and S3D), while no specific binding was detected on the Villin or $36 B 4$ gene promoters (Figures $6 \mathrm{E}, \mathrm{F}$ and $\mathrm{S} 3 \mathrm{E}, \mathrm{F}$ ). Given the intriguing result of TR $\alpha 1$ binding to WRE regions, we used the software NUBISCAN (http://www.nubiscan.unibas.ch) to search for the presence of putative nuclear receptor binding sites in silico. No TREs were found within the Axin 2 or $c-M y c$ genomic regions containing the WREs analyzed (data not shown).

\section{Discussion}

The process of intestinal maturation and its homeostatic control by TH-TR $\alpha 1$ in mice results from a complex modulation of genes and signaling pathways, including the WNT, Notch and BMP [16]. The WNT pathway is considered a major signaling modulator of the physiological and pathological cell proliferation in the intestinal epithelium [41]\#. Moreover, due to its direct action on epithelial stem cells, this pathway is also a main regulator of epithelial homeostasis [41]. Interestingly, the superfamily of the Nuclear Hormone Receptors (NHR), to which TR $\alpha 1$ belongs, displays several levels of functional and physical interactions with the WNT pathway $[22,23]$. Although this interaction is relatively conserved among NHRs, there are however several differences. Some NHRs, such as VDR, PPAR $\gamma$, and AR, are found in a complex with both $\beta$-catenin and Tcf/Lef, while others, such as $\mathrm{ER}$ and $\mathrm{AR}$, can be found in a complex with Tcf/Lef in the absence of $\beta$-catenin [42-46]. The functional outcomes of these protein-protein interactions can also differ depending on the NHR. Generally speaking, $\beta$-catenin synergistically activates NHR activity, and NHR reciprocally deactivates or even represses $\beta$ catenin activity $[22,23]$. This effect can be attributed to a large number of mechanisms involving E-cadherin expression, the competition between Tcf/Lef and NHRs for binding to $\beta$-catenin and/or p300 or the recruitment of co-repressors such as TLE, NGoR, and SMRT [22,23]. However, these interactions are highly dependent on the cellular context and can create divergent effects. For example, PPAR $\gamma$, whose expression and activity is negatively regulated by WNT in mesenchymal stem cells, undergoes positive regulation of the WNT signal in colon cancer cells [45]. A similar phenomenon is reported for VDR, which super-activates $\beta$-catenin activity in keratinocytes [42]\#, but attenuates it in colorectal cancer [25,28,47]. In this context, the physical interaction between $\mathrm{TR} \alpha \mathrm{l}$ and the transcriptional effectors of WNT was an attractive field of investigation. In fact, it had been previously shown that TR $\beta 1$ and $\beta$-catenin can interact directly to form a complex in thyrocytes [24]. This study, however, did not define the involvement of Tcf4 or the effect on TR $\beta 1$ activity. In this study, we have provided the first evidence that TR $\alpha 1$ interacts with $\beta$-catenin. Moreover, this interaction also involves Tcf4. There are two major differences between the interaction of $\mathrm{TR} \alpha 1 / \beta$-catenin/Tcf4 in the intestinal epithelium and that of $T R \beta 1 / \beta$-catenin in thyrocytes. The first is the destabilization of the TR $\beta 1 / \beta$-catenin complex by the hormone T3 [24], while we found no evidence for any T3-mediated effect on $\mathrm{TR} \alpha \mathrm{l} / \beta$-catenin/Tcf4. The second is the action of the complex on the WNT pathway. In fact, TR $\beta 1$ induces the degradation of $\beta$-catenin [24], but TR $\alpha 1$ stabilizes it and activates WNT $[9,15]$. It is worth noting that TR $\alpha 1$ and TR $\beta 1$ often play opposite roles $[5,48]$, and differences in the cell context may also explain these divergences.

Previously, we described several levels of complex relationships between WNT and the TR $\alpha 1$ pathways [10]\#. First, we showed that TR $\alpha 1$ induces WNT activation and enhances cell proliferation $[15,16]$. Second, we demonstrated a synergy between these two pathways during the process of intestinal tumorigenesis [9]. Finally, the third level of regulation outlined herein validates the positive action of TR $\alpha 1$ on WNT through a protein-protein interaction. In light of these new results, we propose that an intriguing feedback loop can also occur and that WNT overactivation likely decreases TR $\alpha 1$ transcriptional activity (proposed model of action in Figure 7). However, from our results, we cannot definitively conclude that this protein-protein interaction involves only the three partners we analyzed, as other factors that have not yet been identified may also participate in the complex.

It has been shown that the functional interactions between signaling pathways involved in gut homeostasis can have a primary importance in the process of cell transformation. This is the case, for instance, of the synergy between WNT and Notch [49] or WNT and TR $\alpha 1$ [9]. In both examples, Notch and TR $\alpha 1$ induce increased cell proliferation, which is likely to determine an early mutagenic event in the Apc gene, and finally an acceleration of the tumorigenic process. We have shown that TR $\alpha 1$ interacts with the $\beta$-catenin/Tcf4 complex and speculate that this interaction might play a key role during the process of intestinal tumorigenesis by stabilizing the WNT effectors on their target genes. We could not observe, however, a clear-cut difference in the expression level of the WNT targets in the adenocarcinoma of different genotypes. One possibility is that once the tumoral program is completed, the molecular differences may be less apparent at the mRNA level. In addition, colon cancer is genetically heterogeneous and is composed of distinct subpopulations [50,51]. Hence, interpretation of 


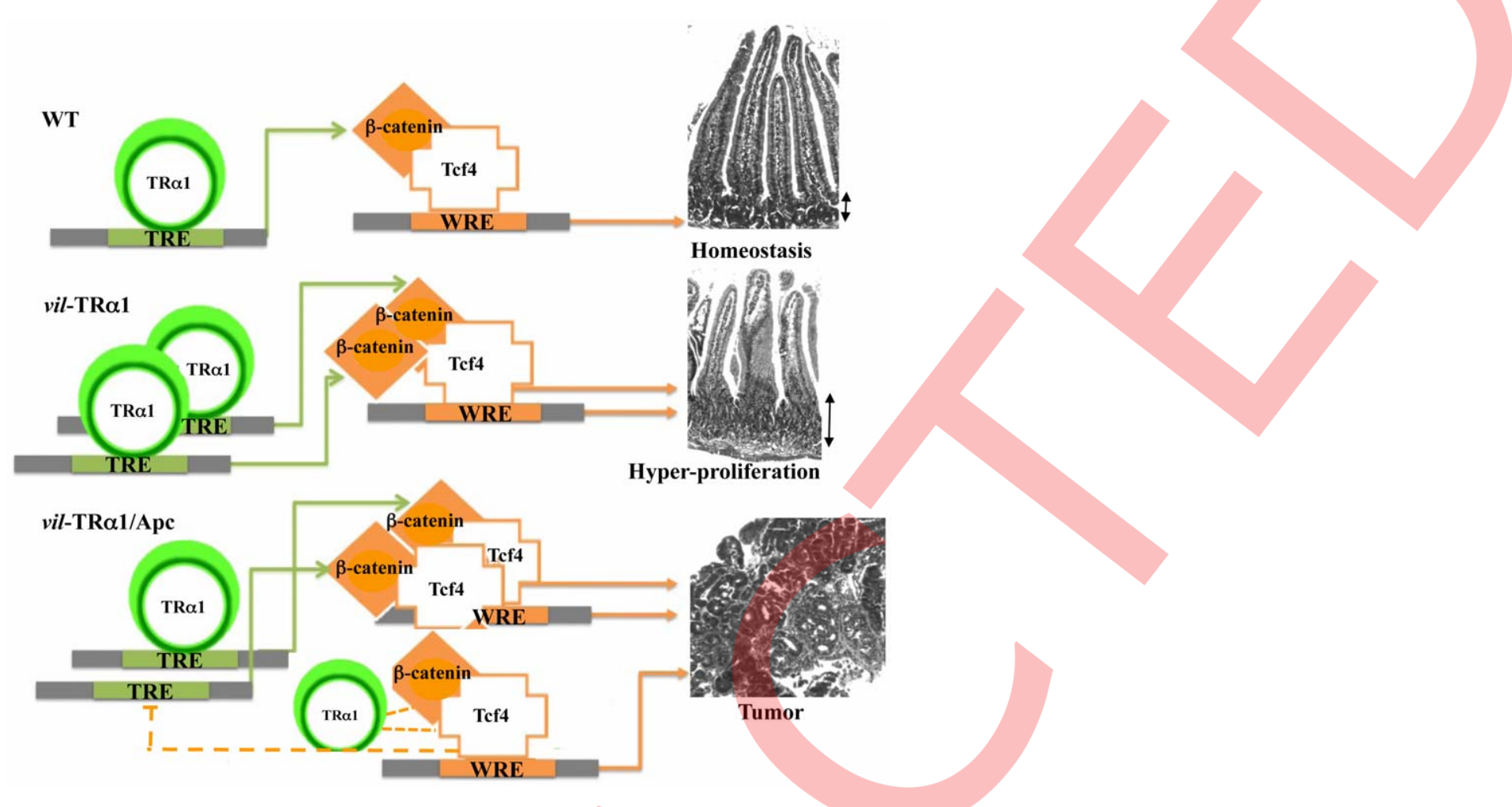

Figure 7. Proposed molecular model for the action of TRa1 in controlling the WNT signaling pathway in the intestine. In physiological conditions (WT), TR $\alpha 1$ binding on TREs positively regulates the expression and stabilization of $\beta$-catenin, and then contributes to maintaining tissue homeostasis. In vil-TR $\alpha 1$ mice, there is an increased level of $\beta$-catenin expression and stabilization that leads to WNT activation and hyperproliferation. In vil-TR $\alpha 1 / A p c$ mice, the stronger $\beta$-catenin stabilization and Tcf4 overexpression might be responsible of the shift in TR $\alpha 1$ binding from TREs to WREs. The physical interaction between TR $\alpha 1$ and $\beta$-catenin/Tcf4 we showed can explain its presence on the WREs. We speculate that this is a novel mechanism of WNT induction promoting the activation and/or the acceleration of the tumorigenic process. TREs, Thyroid hormone response elements; WREs, WNT response elements. Solid lines indicate genomic actions; dotted lines represent the speculative model of a negative regulatory loop involving non-genomic actions and eventually other(s) factor(s). Double black arrows indicate crypt width in WT and vil-TR $\alpha 1$ intestinal sections.

doi:10.1371/journal.pone.0034162.g007

results from a comparative gene expression analysis in whole tumors can be hampered by such heterogeneity. In support of both assumptions, an upregulation of the WNT targets in the normal mucosa of the vil-TR $\alpha 1 / \mathrm{Apc}$ mice is evident and might play a critical role during the early steps of gut tumorigenesis. With regard to the direct targets of $\mathrm{TR} \alpha 1$, the overexpression of $\beta$ catenin/Tcf4 clearly inhibits their TR $\alpha 1$-dependent upregulation, but it does not affect the expression of the $T R \alpha 1$ indirect targets Ccnb1 and $C d c 2 a$. It is probable that other transcription factors and compensatory mechanism(s) occurring in vivo may also be responsible for their expression levels.

Our results suggest that the binding of TR $\alpha 1$ to its DNA targets is shifted to the WNT targets when the $\beta$-catenin/Tcf4 protein levels increase (Figure 7). This condition is typical of intestinal cancers characterized by mutations in components of the WNT pathway (including Apc, Ctnnb1 and Axin2) [50,52] that allow for $\beta$-catenin increase and stabilization. With regard to Tcf4 expression, we observed its upregulation in the tumors of both Apc and vil-TR $\alpha 1$ / Apc mice. Interestingly, we also observed an increased expression of Tcf4 in the normal mucosa of the vil-TR $\alpha 1 /$ Apc mice but not in the normal mucosa of the Apc animals. Taken together, our previous and present data strongly suggest that even if we refer to "vil-TR $\alpha 1$ / Apc mice normal mucosa", this may only be indicative of the morphological appearance. Indeed, from a molecular standpoint, it differs in several ways from the WT mucosa [9] (this paper) and clearly indicates an altered pre-cancerous status.
In conclusion, we have shown that in the context of intestinal lesions, TR $\alpha 1$ reshapes its function and induces specific genomic and non-genomic events. TR $\alpha 1$ transcriptional activity was negatively modulated by increased levels of $\beta$-catenin/Tcf4 and the binding to its target genes was also impaired. Interestingly, TR $\alpha 1$ was recruited to WNT target genes specifically within the lesions. This dual mechanism can have important repercussions and opens a new perspective in studying the sequential events of tumor development. An obvious speculation is that $\beta$-catenin/ Tcf4 activity on their target genes could be reduced in the absence of $\mathrm{TR} \alpha 1$. Our preliminary results from $\mathrm{TR} \alpha^{0 / 0} / \mathrm{Apc}$ mice sustain this assumption (our unpublished observations); however, it is necessary to further confirm this result to account for the delay in or absence of tumor formation in these animals. A future challenge will be to define how complex cross-regulation and integrated networks, such as those involving the NHR and WNT pathways, can affect the cellular phenotype when signals are altered. These data will surely be of importance for translational research and could help explain the contradictory results concerning NHRs and carcinogenesis.

\section{Materials and Methods}

\section{Animals and sample collection}

We used vil-TR $\alpha 1$, vil-TR $\alpha 1 / \mathrm{Apc}, \mathrm{Apc}^{+/ 1638 \mathrm{~N}}$ and wild-type animals [9]. Mice were housed and maintained with approval 
from the animal experimental committee of the Ecole Normale Supérieure de Lyon (Lyon, France) and in accordance with European legislation on animal care and experimentation. Lyon University's "Comité d'Evaluation Commun au Centre Léon Bérard, à l'Animalerie de transit de l'ENS, au PBES et au laboratoire P4" (CECGAPP) and the "the Comité Régional d'Ethique pour l'Expérimentation Animale» (CREEA) approved all animal studies (agreement no. 0230). Animals were sacrificed, and the intestine (normal mucosae and tumors) was quickly removed. We recovered tumors and normal portions of the mucosa under a binocular microscope (Olympus) and froze them in liquid nitrogen for RNA extraction or the ChIP assay.

\section{Intestinal epithelium primary cultures, immunolabelling and western blot}

Intestinal epithelial primary cultures were derived from 4-6 day old neonatal mice according to Evans and colleagues [53]. Briefly, after sacrifice, the entire small intestine was removed. The epithelium was isolated as intact organoids by enzymatic dissociation using collagenase type XI (Sigma) and dispase (Boehringer Mannheim), followed by physical disaggregation and filtration on gauze. Organoids were plated in Dulbecco's modified Eagle medium (DMEM, Invitrogen) supplemented with 2.5\% heatinactivated fetal calf serum (Gibco), $20 \mathrm{ng} / \mathrm{ml}$ epidermal growth factor (Sigma), and insulin-transferrin-selenium diluted 1/100 (Sigma). Culture surfaces were coated with Matrigel ${ }^{\mathrm{TM}}$ Basement Membrane Matrix (BD Biosciences). For immunolabeling experiments, cover-slips were inserted in the wells before coating. For proliferation studies, $10 \mu \mathrm{M}$ BrdU was added to the culture medium for an overnight incubation. The purity of the epithelial colonies was analyzed by immunolabeling for specific markers: epithelial cells: anti-cytokeratins (ICN); fibroblasts: anti-vimentin (Sigma); smooth muscle cells: anti-smooth muscle actin (Sigma). For treatment experiments, after 2 days of culture, the vehicle alone or $10^{-7} \mathrm{M} \mathrm{T} 3$ and/or $10 \mathrm{ng} / \mu \mathrm{l}$ of recombinant Wnt3a (R\&D system) was added to the culture medium for 24 hours.

Immunolabeling was performed on $2 \%$ paraformaldehyde-fixed cultures, as previously described by Rezza and colleagues [32]. We used anti-Ki67 (Labvision MBL) and anti- $\beta$-catenin (Santa Cruz) primary antibodies.

Western blot $(\mathrm{WB})$ was performed on whole-protein extracts obtained by homogenizing the samples in RIPA buffer, as described in [32]. Whole protein extracts (50 $\mu \mathrm{g} /$ lane) from cells maintained in the different experimental conditions were analyzed. We used anti-activated $\beta$-catenin (Upstate) and anti-actin (Sigma).

\section{Cell lines and transfection experiments}

This study was performed on the human Caco2 colorectal cancer cell line (from the American Type Culture Collection). Caco2 cells (50,000 cells/well in 24 multiwell plates) were cultured in DMEM supplemented with $10 \%$ heat- inactivated fetal calf serum. We used the following vectors: pGl2-DR4-Luc and pGl2mutDR4-Luc (200 ng/well) and pGS5-TR $\alpha 1$ [15] (100 ng/well); TopFlash and FopFlash (Upstate; 200 ng/well); pCIneo-b-cateninXL (100 ng/well), Evr2-Tcf4E (100 ng/well; kind gift of Professor Waterman, UC Irvine, USA); pRL-CMV (1 ng/well; Promega). The vectors were transfected using the Exgen transfection reagent (Euromedex). For the T3 treatments, the cells were maintained in thyroid hormone-depleted serum [35]. T3 $\left(10^{-6} \mathrm{M}\right)$ or vehicle alone was added to the culture medium 24 hours before the end of the culture. Luciferase activity was measured 48 hours after transfection using the luciferase dual system (Promega).

\section{Coimmunoprecipitation assay and western blot analysis}

Coimmunoprecipitation (CoIP) studies were conducted on Caco2 cells using a slightly modified procedure described by Guigon and colleagues [24]. Nuclear and cytoplasmic extracts were pre-cleared with Protein A magnetic beads (Invitrogen) for 4 hours at $4^{\circ} \mathrm{C}$. Immunoprecipitations of endogenous complexes were conducted overnight at $4^{\circ} \mathrm{C}$ with anti-Tcf4 (Santa Cruz), anti- $\beta$-catenin (Santa Cruz), anti-TR $\alpha 1$ [15] antibodies. As negative controls, the extracts were incubated with rabbit IgG (Promega). The complexes were washed and then recovered with Protein A magnetic beads. Immunoprecipitated proteins were subjected to SDS-PAGE and western blot analysis by using the different antibodies mentioned above. Whole proteins $(50 \mu \mathrm{g} /$ lane) on the blots were stained with Ponceau red. The nuclear extracts and loading in inputs were examined by using an antiHistone $\mathrm{Hl}$ antibody (Santa Cruz).

\section{RNA extraction and RTqPCR analysis}

RNA was extracted from tissue samples using the Qiagen RNeasy Kit (Qiagen). To avoid the presence of contaminating DNA, DNase digestion was performed on all preparations. Reverse transcription was performed using MuMLV reverse transcriptase (Promega) on $1 \mu \mathrm{g}$ of total RNA using random hexanucleotide priming (Promega) according to the manufacturer's instructions. For the primary cultures, RNA was extracted using the Absolutely RNA Nanoprep Kit (Stratagene). Reverse transcription was performed using the SuperScript III First-Strand Synthesis SuperMix for qRT-PCR (Invitrogen) on $300 \mathrm{ng}$ of total RNA. All of the cDNA samples were purified using the Qiagen PCR Purification Kit (Qiagen) before use for the qPCR experiments. The qPCR was performed with SYBR green PCR master mix (Qiagen) in an MxP3000 apparatus (Stratagene). The data from the qPCR were normalized to $36 \mathrm{~B} 4$ levels for each sample. The primers are listed in Table S1A.

\section{Electrophoretic mobility shift assay (EMSA)}

Tcf4, $\beta$-catenin, TR $\alpha 1$ and $\operatorname{RXR} \alpha$ full-length cDNAs were transcribed/translated in vitro using the quick TNT kit (Promega) according to the manufacturer's protocol. We performed the EMSA assay on the DR4-radiolabeled probe, as previously described [18], in a buffer similar to that of the CoIP: $3 \%$ glycerol, $20 \mathrm{mM}$ HEPES, $3 \mathrm{mM}$ DDT, $0.3 \%$ NP40, $100 \mathrm{mM}$ $\mathrm{KCl}$, protease inhibitor cocktail (Roche), $4 \mathrm{mM}$ spermidine, and poly-dI-dC $(1.5 \mu \mathrm{g})$. Where indicated, anti-TR $\alpha 1$ [15] and antiTcf4 (Santa Cruz) antibodies were included in the reaction mix.

\section{Chromatin immunoprecipitation (ChIP)}

The ChIP study was performed on $10 \mathrm{mg}$ of samples collected from the intestine of vil-TR $\alpha 1 /$ Apc (healthy mucosa and tumors) and WT mice. The samples were minced with a razor blade and crosslinked with $1 \%$ formaldehyde at room temperature for 15 minutes. The crosslinking reaction was stopped by the addition of glycine to a final concentration of $0.125 \mathrm{M}$, and the samples were incubated at room temperature for 5 minutes. The samples were then centrifuged at $200 \mathrm{~g}$ to pellet the pieces. The fragments were washed once in cold PBS containing protease inhibitor cocktail (Roche) and then disaggregated by 10 strokes in a Dounce homogenizer. The resulting homogenate was centrifuged at $2000 \mathrm{~g}$, the pellet recovered was then incubated in SDS buffer ( $1 \%$ SDS, $50 \mathrm{mM}$ TRIS pH 8.1, $10 \mathrm{mM} \mathrm{EDTA)} \mathrm{on} \mathrm{ice} \mathrm{for}$ 10 minutes. After 15 minutes of sonication (30 sec on/30 sec off cycles, Biodisruptor), the samples were centrifuged at maximum speed at $4^{\circ} \mathrm{C}$, and the supernatant was recovered and quantified 
by Nanodrop (ND-1000 UV-Vis Spectrophotometer, NanoDrop Technologies). The same amount of each sample was diluted 1:10 in dilution buffer $(0.01 \%$ SDS, $1.1 \%$ Triton X-100, $1.2 \mathrm{mM}$ EDTA, 16.7 mM Tris-HCl, pH 8.1, 167 mM NaCl). After preclearing with Protein A magnetic beads (Invitrogen), each sample was divided into four samples, and the precipitation was performed using $9 \mu \mathrm{g}$ of each antibody (anti-Tcf4, Santa Cruz; anti $\beta$-catenin, Santa Cruz; anti-TR $\alpha 1$ [15] or rabbit IgG). At the end of the reaction and washing steps, the complexes were recovered using protein A magnetic beads. The DNA was extracted after Proteinase K (Fermentas) and phenol-chloroform treatments. Specific DNA fragments were analyzed by qPCR using a SYBR green PCR master mix (Qiagen) in an MxP3000 apparatus (Stratagene). The primers designed to amplify the genomic regions containing: 1) TREs we previously described $[15,16]$; 2) WREs described in literature [39,40]; and 3) the villin and Rplpo (36B4) promoters, as negative controls [15]. Primer sequences are listed in Table $\mathrm{S} 1 \mathrm{~B}$; the Ppia gene was used in all reactions as internal control.

\section{Supporting Information}

Figure S1 RT-qPGR analysis in mice. (A, B) Analysis of TR $\alpha 1$-direct target genes in 1 month-old WT, vil-TR $\alpha 1$ and vilTR $\alpha 1 / A p c$ mice. RT-qPCR analysis was performed to evaluate the mRNA levels of Ctnnbl and Sfrp2. Values represent fold change \pm sd after normalization to the wild-type (WT) animals. *: $\mathrm{P}<0.05, * *: \mathrm{P}<0.01$ compared with the $\mathrm{WT}$ by two-tailed Student's t-test $(\mathrm{n}=4)$. $(\mathrm{C})$ Analysis of iodothyronine deiodinase selenoenzyme type 1 (Diol) mRNA expression in WT, vil-TR $\alpha 1$, Apc and vil-TR $\alpha 1 / A p c$ mice. RT-qPCR experiments were performed in the intestine of 6 -month-old mice. Values represent specific mRNA expression \pm sd after normalization to $36 \mathrm{~B} 4$ $(\mathrm{n}=4)$. N, normal mucosa; $\mathrm{T}$, tumor.

(PDF)

Figure S2 Physical interaction between TR $\alpha 1$ and the $\beta$ catenin in nuclei. Cellular lysates from Caco2 cells, maintained in T3-depleted (-) or T3-supplemented (+) serum, were fractionated into nuclear $(\mathrm{N})$ and cytoplasmic $(\mathrm{C})$ extracts. Lysates were immunoprecipitated with antibodies directed against endogenous $\beta$-catenin (upper panel) or TR $\alpha 1$ (lower panel), and the WB analysis of the indicated proteins was performed. Rabbit IgG was used as negative control. Ponceau red was used as whole-protein (50 $\mu \mathrm{g} /$ lane) loading control. Histone $\mathrm{Hl}$ was used to check the enrichment and was the loading control for the nuclear proteins in

\section{References}

1. Barker N, Ridgway RA, van Es JH, van de Wetering M, Begthel H, et al. (2009) Crypt stem cells as the cells-of-origin of intestinal cancer. Nature 457: 608-611.

2. Stappenbeck TS, Wong MH, Saam JR, Mysorekar IU, Gordon JI (1998) Notes from some crypt watchers: regulation of renewal in the mouse intestinal epithelium. Curr Opin Cell Biol 10: 702-709.

3. Sancho E, Batlle E, Clevers H (2004) Signaling pathways in intestinal development and cancer. Annu Rev Cell Dev Biol 20: 695-723.

4. Buske P, Galle J, Barker N, Aust G, Clevers H, et al. (2011) A comprehensive model of the spatio-temporal stem cell and tissue organisation in the intestinal crypt. PLoS Comput Biol 7: e1001045.

5. Kress E, Samarut J, Plateroti M (2009) Thyroid hormones and the control of cell proliferation or cell differentiation: paradox or duality? Mol Cell Endocrinol.

van der Flier LG, Clevers H (2009) Stem cells, self-renewal, and differentiation in the intestinal epithelium. Annu Rev Physiol 71: 241-260.

7. Radtke F, Clevers H, Riccio O (2006) From gut homeostasis to cancer. Curr Mol Med 6: 275-289.

8. Humphries A, Wright NA (2008) Colonic crypt organization and tumorigenesis. Nat Rev Cancer 8: 415-424.

9. Kress E, Skah S, Sirakov M, Nadjar J, Gadot N, et al. (2010) Cooperation between the thyroid hormone receptor TRalphal and the WNT pathway in the induction of intestinal tumorigenesis. Gastroenterology 138: 1863-1874. the inputs. The pictures are representative of at least three independent experiments.

(PDF)

Figure S3 Ghromatin occupancy of TR $\alpha 1, \beta$-catenin and Tcf4 on genomic regions of target genes. ChIP analysis was performed with chromatin isolated from the intestine of WT or vilTR $\alpha 1 /$ Apc mice (healthy mucosa and tumor) and immunoprecipitated with anti-TR $\alpha 1$, anti- $\beta$-catenin, anti-Tcf4 antibodies or rabbit IgG (negative control). qPCR was performed using specific primers covering the TRE of Sfrp2 (A) and Ctnnbl (B), the WRE of Axin2 $(\mathrm{C})$ and c-Myc (D) or the promoters of Villin $(\mathrm{E})$ and 36B4 (F); the Ppia gene was used as internal control. Histograms represent the specific-DNA enrichment in each sample immunoprecipitated with the indicated antibody. The black bar in A-D delineates the threshold of binding specificity determined by the IgG non-specific binding. N, normal mucosa; $\mathrm{T}$, tumor.

(PDF)

Figure S4 Electromobility Shift Assay on DR4 response element. (A) EMSA analysis was performed to examine the TR $\alpha 1 / \beta$-catenin/Tcf4 complex formation on a DR4-radiolabeled probe. In vitrotranscribed/translated proteins were added to the mixture as indicated, and the DNA-protein complexes were separated by native gel electrophoresis. Specific antibodies were added to assess the protein $[\mathrm{s}]$ involved in the complex. In all of the conditions, only TR $\alpha 1$ alone binds to the labeled probe. (B) EMSA performed in the presence of the $\mathrm{TR} \alpha \mathrm{l}$ transcriptional partner $\operatorname{RXR} \alpha$. It is worth noting that even in the presence of $\operatorname{RXR} \alpha$, there is no $\beta$-catenin/Tcf4 binding to TR $\alpha 1$ on a TRE.

(PDF)

Table S1 (A) Oligonucleotides used for the RT-qPCR study. (B) Oligonucleotides used for qPCR study after ChIP assay.

$(\mathrm{PDF})$

\section{Acknowledgments}

We gratefully acknowledge Nadine Aguilera for animal handling. We thank Professor Jacques Samarut for helpful discussion and scientific support at the early steps of this work. We are indebted to Professor Marian Waterman for the expression vectors.

\section{Author Contributions}

Conceived and designed the experiments: MS MP. Performed the experiments: MS SS INL JN. Analyzed the data: MS SS INL DA MP. Wrote the paper: MS MP. Read and approved the final manuscript: MS SS INL JN DA MP.

10. Sirakov M, Plateroti M (2011) The thyroid hormones and their nuclear receptors in the gut: From developmental biology to cancer. Biochim Biophys Acta 1812: 938-946.

11. Flamant F, Samarut J (2003) Thyroid hormone receptors: lessons from knockout and knock-in mutant mice. Trends Endocrinol Metab 14: 85-90.

12. Yen PM, Ando S, Feng X, Liu Y, Maruvada P, et al. (2006) Thyroid hormone action at the cellular, genomic and target gene levels. Mol Cell Endocrinol 246: 121-127.

13. Puzianowska-Kuznicka M, Pietrzak M, Turowska O, Nauman A (2006) Thyroid hormones and their receptors in the regulation of cell proliferation. Acta Biochim Pol 53: 641-650.

14. Gauthier K, Plateroti M, Harvey CB, Williams GR, Weiss RE, et al. (2001) Genetic analysis reveals different functions for the products of the thyroid hormone receptor alpha locus. Mol Cell Biol 21: 4748-4760.

15. Plateroti M, Kress E, Mori JI, Samarut J (2006) Thyroid hormone receptor alphal directly controls transcription of the beta-catenin gene in intestinal epithelial cells. Mol Cell Biol 26: 3204-3214.

16. Kress E, Rezza A, Nadjar J, Samarut J, Plateroti M (2009) The frizzledrelated sFRP2 gene is a target of thyroid hormone receptor alphal and activates beta-catenin signaling in mouse intestine. J Biol Chem 284: 1234 1241 . 
17. Gottardi CJ, Wong E, Gumbiner BM (2001) E-cadherin suppresses cellular transformation by inhibiting beta-catenin signaling in an adhesion-independent manner. J Cell Biol 153: 1049-1060.

18. Brantjes H, Barker N, van Es J, Clevers H (2002) TCF: Lady Justice casting the final verdict on the outcome of Wnt signalling. Biol Chem 383: 255-261.

19. Widelitz R (2005) Wnt signaling through canonical and non-canonical pathways: recent progress. Growth Factors 23: 111-116.

20. de Lau W, Barker N, Clevers H (2007) WNT signaling in the normal intestine and colorectal cancer. Front Biosci 12: 471-491.

21. Radtke F, Clevers H (2005) Self-renewal and cancer of the gut: two sides of a coin. Science 307: 1904-1909.

22. Beildeck ME, Gelmann EP, Byers SW (2010) Cross-regulation of signaling pathways: an example of nuclear hormone receptors and the canonical Wnt pathway. Exp Cell Res 316: 1763-1772.

23. Mulholland DJ, Dedhar S, Coetzee GA, Nelson CC (2005) Interaction of nuclear receptors with the Wnt/beta-catenin/Tcf signaling axis: Wnt you like to know? Endocr Rev 26: 898-915.

24. Guigon CJ, Zhao L, Lu C, Willingham MC, Cheng SY (2008) Regulation of beta-catenin by a novel nongenomic action of thyroid hormone beta receptor. Mol Cell Biol 28: 4598-4608.

25. Shah S, Islam MN, Dakshanamurthy S, Rizvi I, Rao M, et al. (2006) The molecular basis of vitamin D receptor and beta-catenin crossregulation. Mol Cell 21: 799-809.

26. Botrugno OA, Fayard E, Annicotte JS, Haby C, Brennan T, et al. (2004) Synergy between LRH-1 and beta-catenin induces G1 cyclin-mediated cell proliferation. Mol Cell 15: 499-509.

27. Chesire DR, Isaacs WB (2002) Ligand-dependent inhibition of beta-catenin/ TCF signaling by androgen receptor. Oncogene 21: 8453-8469.

28. Easwaran V, Pishvaian M, Salimuddin, Byers S (1999) Cross-regulation of betacatenin-LEF/TCF and retinoid signaling pathways. Curr Biol 9: 1415-1418.

29. Fodde R, Edelmann W, Yang K, van Leeuwen C, Carlson C, et al. (1994) A targeted chain-termination mutation in the mouse Apc gene results in multiple intestinal tumors. Proc Natl Acad Sci U S A 91: 8969-8973.

30. Gaspar C, Fodde R (2004) APC dosage effects in tumorigenesis and stem cell differentiation. Int J Dev Biol 48: 377-386.

31. Bianco AC, Kim BW (2006) Deiodinases: implications of the local control of thyroid hormone action. J Clin Invest 116: 2571-2579.

32. Gereben B, Zavacki AM, Ribich S, Kim BW, Huang SA, et al. (2008) Cellular and molecular basis of deiodinase-regulated thyroid hormone signaling. Endocr Rev 29: 898-938.

33. Kengaku M, Capdevila J, Rodriguez-Esteban C, De La Pena J, Johnson RL, et al. (1998) Distinct WNT pathways regulating AER formation and dorsoventral polarity in the chick limb bud. Science 280: 1274-1277.

34. Rezza A, Skah S, Roche G, Nadjar J, Samarut J, et al. (2010) The overexpression of the putative gut stem cell marker Musashi-1 induces tumorigenesis through Wnt and Notch activation. J Cell Sci 123: 3256-3265.

35. Arce L, Yokoyama NN, Waterman ML (2006) Diversity of LEF/TCF action in development and disease. Oncogene 25: 7492-7504.

36. Waterman ML (2004) Lymphoid enhancer factor/T cell factor expression in colorectal cancer. Cancer Metastasis Rev 23: 41-52.

37. Samuels HH, Stanley F, Casanova J (1979) Depletion of L-3,5,3'-triiodothyronine and L-thyroxine in euthyroid calf serum for use in cell culture studies of the action of thyroid hormone. Endocrinology 105: 80-85.
38. Korinek V, Barker N, Morin PJ, van Wichen D, de Weger R, et al. (1997) Constitutive transcriptional activation by a beta-catenin-Tcf complex in APC- /colon carcinoma. Science 275: 1784-1787.

39. Mahmoudi T, Boj SF, Hatzis P, Li VS, Taouatas N, et al. (2011) The leukemiaassociated Mllt10/Af10-Dot1l are Tcf4/beta-catenin coactivators essential for intestinal homeostasis. PLoS Biol 8: e1000539.

40. Hu MC, Rosenblum ND (2005) Smad1, beta-catenin and Tcf4 associate in a molecular complex with the Myc promoter in dysplastic renal tissue and cooperate to control Myc transcription. Development 132: 215-225.

41. Gregorieff A, Clevers $\mathrm{H}$ (2005) Wnt signaling in the intestinal epithelium: from endoderm to cancer. Genes Dev 19: 877-890.

42. Cianferotti L, Cox M, Skorija K, Demay MB (2007) Vitamin D receptor is essential for normal keratinocyte stem cell function. Proc Natl Acad Sci U S A 104: 9428-9433.

43. Amir AL, Barua M, McKnight NC, Cheng S, Yuan X, et al. (2003) A direct beta-catenin-independent interaction between androgen receptor and $\mathrm{T}$ cell factor 4. J Biol Chem 278: 30828-30834.

44. Song LN, Herrell R, Byers S, Shah S, Wilson EM, et al. (2003) Beta-catenin binds to the activation function 2 region of the androgen receptor and modulates the effects of the N-terminal domain and TIF2 on ligand-dependent transcription. Mol Cell Biol 23: 1674-1687.

45. Jansson EA, Are A, Greicius G, Kuo IC, Kelly D, et al. (2005) The Wnt/betacatenin signaling pathway targets PPARgamma activity in colon cancer cells. Proc Natl Acad Sci U S A 102: 1460-1465.

46. El-Tanani M, Fernig DG, Barraclough R, Green G, Rudland P (2001) Differential modulation of transcriptional activity of estrogen receptors by direct protein-protein interactions with the $\mathrm{T}$ cell factor family of transcription factors. J Biol Chem 276: 41675-41682.

47. Palmer HG, Gonzalez-Sancho JM, Espada J, Berciano MT, Puig I, et al. (2001) Vitamin D[3] promotes the differentiation of colon carcinoma cells by the induction of E-cadherin and the inhibition of beta-catenin signaling. J Cell Biol 154: 369-387.

48. Cheng SY, Leonard JL, Davis PJ (2010) Molecular aspects of thyroid hormone actions. Endocr Rev 31: 139-170.

49. Fre S, Pallavi SK, Huyghe M, Lae M, Janssen KP, et al. (2009) Notch and Wnt signals cooperatively control cell proliferation and tumorigenesis in the intestine. Proc Natl Acad Sci U S A 106: 6309-6314

50. Yokota J (2000) Tumor progression and metastasis. Carcinogenesis 21: 497-503.

51. Buob D, Fauvel H, Buisine MP, Truant S, Mariette C, et al. (2011) The Complex Intratumoral Heterogeneity of Colon Cancer Highlighted by Laser Microdissection. Dig Dis Sci, In print.

52. Clevers $\mathrm{H}$ (2006) Wnt/beta-catenin signaling in development and disease. Cell 127: 469-480.

53. Evans GS, Flint N, Somers AS, Eyden B, Potten CS (1992) The development of a method for the preparation of rat intestinal epithelial cell primary cultures. J Cell Sci 101: 219-231.

54. Staal FJ, Noort Mv M, Strous GJ, Clevers HC (2002) Wnt signals are transmitted through N-terminally dephosphorylated beta-catenin. EMBO Rep 3: 63-68.

55. van Noort M, Meeldijk J, van der Zee R, Destree O, Glevers H (2002) Wnt signaling controls the phosphorylation status of beta-catenin. J Biol Chem 277: 17901-17905 